\title{
Teaching therapeutics in paediatrics using high fidelity simulation: Knowledge gain and perception among final year medical students
}

\author{
*Thilanka Seneviratne ${ }^{1}$, Kosala Somaratne ${ }^{2}$, Vindhya Alahakoon $^{1}$, Dilan Bandara ${ }^{1}$, Deelaka Bandara ${ }^{1}$
}

Sri Lanka Journal of Child Health, 2020; 49(1): 59-63

\begin{abstract}
Introduction: The art and science of selecting the correct medicine for different diseases is called therapeutics. For students of medicine to learn this, real patients are a need. Yet, there are ethical and safety issues when trainees use patients for learning purposes. If patients and diseases can be mimicked, this problem could be circumvented. High Fidelity Simulations (HFS) is the science and art of mimicking patients and diseases as close as possible to real life scenarios.
\end{abstract}

Objective: To assess the student perception on the use of HFS to teach therapeutics in paediatrics and to assess the knowledge gain.

Method: A group of final year medical students during their professorial paediatric appointment were given the scenarios on status epilepticus and acute severe asthma using HFS, designed to select the correct drugs, formulations, doses, routes of administration, checking and giving the drugs, looking for adverse reactions and managing accordingly. Pre-test and post-test questionnaires were administered to assess the student's knowledge gain. Their perception about the teaching session was assessed using a pre-tested anonymous selfadministered questionnaire in a five-point Likert scale. ( $1=$ strongly disagree, $5=$ strongly agree $)$

Results: Students scored significantly higher in the post-knowledge assessment when compared with the pre-session knowledge assessment $(p<0.001)$. Student perception about the HFS session scored 4 to 5 in the Likert scale. Students mentioned that HFS should be used more often in teaching therapeutics and further mentioned that it is better than small group discussions.

Conclusions: Use of HFS in teaching therapeutics in paediatrics is well received by students. It is an effective method of knowledge gain in therapeutics for medical students.

$\overline{{ }^{1} \text { Faculty of Medicine, University of Peradeniya, Sri }}$ Lanka, ${ }^{2}$ Base Hospital, Rikillagaskada, Sri Lanka

*Correspondence: thilanka.medi@gmail.com

(D) https://orcid.org/0000-0002-4311-3668

(Received on 11 June 2019: Accepted after revision on 12 August 2019)

The authors declare that there are no conflicts of interest

Personal funding was used for the project.

Open Access Article published under the Creative

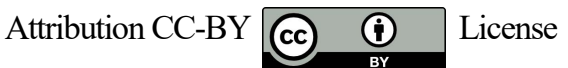

DOI: http://dx.doi.org/10.4038/sljch.v49i1.8900

(Key words: High fidelity simulation, therapeutics, paediatrics)

\section{Introduction}

Teaching therapeutics to medical students seems to be inadequately dealt with in the medical curriculum ${ }^{1,2}$. This causes many inadequacies in their knowledge with regard to drug treatment by the time they qualify as doctors $^{1,2}$. The deficiency may be worse in the specialty of paediatrics where dose calculations, dose frequencies, routes of administrations and formulations are different from adult medicine. Thus, undergraduates need special training in these aspects to master the field.

It is shown that the students learn best when a subject is taught in a context based environment. Context based environment is the environment in which they will be practising later ${ }^{3,4,5}$. Yet, medical students cannot do prescribing in a real ward setting due to ethical and patient safety concerns. This is where the concept of simulation becomes handy. When the simulation is very similar to the real life scenario, it is called high fidelity simulation (HFS). Simulation, in addition to giving a safe and controlled real life experience in treating patients, offers further advantages ${ }^{6}$. This controlled environment can be replicated as and when needed. It can be modulated according to the learning objectives $^{7,8}$. Especially the setting can be modulated to allow the student to experience the adverse effects during drug therapy. As well, different formulations, routes of administration and dose calculations can be done in a safe environment that poses no problem to the real patient. Yet, the lessons learned by the student will be retained in their minds better as they really experience the situation ${ }^{9}$.

HFS is used as a teaching modality currently in many places of medical education and its benefits have been well documented ${ }^{10,11}$. It is especially used to teach management of acute emergencies and trauma scenarios $^{12,13}$. Some studies have reported using HFS for teaching pharmacology to nursing and pharmacy students as well ${ }^{14}$. Using HFS to teach therapeutics in paediatrics to undergraduates is a novel teaching method. We introduced this teaching method to the students during their final year training in paediatrics. Status epilepticus and acute severe asthma are common paediatric emergencies which students are likely to face in their future medical life. Knowing the therapeutics well is an essential part of the proper management of these emergencies ${ }^{13,15}$. Thus, we selected the above scenarios to introduce this new teaching method. 
Objectives

- To assess the student perception on the use of high fidelity patient simulation in teaching therapeutics in paediatrics.

- To assess the knowledge gain in therapeutics with the use of HFS.

\begin{abstract}
Method
Participants: A group of final year medical students in the Faculty of Medicine, University of Peradeniya, Sri Lanka were included in the study during their professorial paediatric appointment. Students who volunteered were included. The number of participants for the simulated session on status epilepticus was 47 while that for acute severe asthma was 38 .
\end{abstract}

Design: An introduction regarding the teaching session was given to the whole group of students before the simulated sessions. They were briefed about the scenario and learning outcome. Students were subgrouped into smaller groups of 5-6 students. Each group of students was given the opportunity to do the simulated scenarios. The initial briefing was given for 10 minutes, then the simulation ran for 20 minutes followed by debriefing for 10 minutes. The same final year group was given the opportunity to do scenarios on status epilepticus and acute severe asthma. Sessions were spaced by one week. High fidelity patient simulator (Sim-man Essential) was used for the simulations. A simulated nurse and a parent were used to direct the scenario in the designed plan. Students were given the opportunity to choose the correct drugs, formulations, decide on a dose, and route of administration and check and give the drugs assisted by the simulated nurse. They were encouraged to look for complications, adverse reactions to drugs and manage accordingly. The technical operator and the machine were placed outside the session room to reduce any disturbance to the students.

Evaluation and assessment: A questionnaire, adapted from the studies published by Pal B, et al ${ }^{13}$, Via DK, et $a l^{16}$ and Branch $\mathrm{C}^{14}$, was modified and developed to assess student perception on the teaching method, content, learning outcome and the perceived stress by the students. Student perception about each simulated teaching session and the stress score was assessed using this pre-tested, anonymous, self-administered questionnaire. All items in the questionnaire on simulated sessions were in a five point Likert scale, where $1=$ strongly disagree and $5=$ strongly agree. Items in the questionnaire on perceived stress were also graded as 1 to $5(1=$ no stress and $5=$ maximum stress). The same questionnaire was given to each student presession and post-session. In addition to the above, students were also given a pre-test and post-test on the management of acute severe asthma and status epilepticus to assess their knowledge of them. Each student was assigned an identification number to keep them anonymous.

Data analysis: Data were analysed using SPSS version 23. Descriptive statistics were calculated, median and quartiles for the categorical data. Mean and the standard deviation were calculated for the pre-test and post-test questionnaires on knowledge gain. The total pre-test and post-test marks for the knowledge questionnaire were compared using the Wilcoxon signed rank test. Wilcoxon signed rank test was used to compare the total stress scores of status epilepticus session and the asthma session. Assessments of the two sessions were analysed separately.

Ethical approval: Ethical approval was taken from the ethical review committee, Faculty of Medicine, University of Peradeniya, Sri Lanka. No: 2018/EC/32

\section{Results}

The number of participants for the simulated session on status epilepticus was 47 while that for acute severe asthma was 38 .

Knowledge gain: The mean score of total marks obtained for pre-test and post-test of acute severe asthma was $63 \%$ and $80 \%$ respectively $(p<0.001)$. For status epilepticus, it was $33 \%$ and $72 \%$ respectively $(\mathrm{p}<0.001)$.

Stress assessment: There was a reduction in stress in the items students mentioned as high and moderate stress at the first session when compared with the second session. However, students still mentioned "need to do well," need to participate in the scenario", "stress due to my performance anxiety", "I am worried about the patient outcome" "feeling of incompetence in managing the patient" as moderate stress (median 3 ) at the end of the last teaching session.

Perception of the simulated session: The median and quartiles for the pre- and post-questionnaire on teaching method, content, learning outcome of simulation and feedback given for the two sessions are given in table 1 .

Students agreed that the session level was appropriate to their present level of knowledge and experience, sessions encouraged their active participation and that the sessions resembled a real life situation (Median 4). Students strongly agreed that the simulated sessions were better than small group discussions, and HFS is an effective tool to teach clinical drug therapy in status epilepticus and acute severe asthma (Median 5). 
Table 1: Student responses to post simulation assessment

\begin{tabular}{|c|c|c|}
\hline \multirow[t]{2}{*}{ Item } & Status epilepticus & Acute asthma \\
\hline & Median (Q1,Q3) & Median(Q1,Q3) \\
\hline Session level was appropriate to my present level of knowledge and experience & $4(3,4)$ & $4(4,4)$ \\
\hline It encouraged my active participation & $4(4,5)$ & $4(4,5)$ \\
\hline The session resembled a real life situation & $4(4,5)$ & $4(4,5)$ \\
\hline It helped me to think quickly & $4(4,5)$ & $4(4,5)$ \\
\hline Time for the scenario was adequate & $4(4,4.25)$ & $4(4,5)$ \\
\hline Time for initial briefing was adequate & $4(4,4)$ & $4(4,4)$ \\
\hline Time for debriefing was adequate & $4(4,5)$ & $4(4,5)$ \\
\hline Debriefing helped me to learn better & $4(4,5)$ & $4(4,5)$ \\
\hline This was a valuable use of my time & $4(4,5)$ & $5(4,5)$ \\
\hline I want to have further sessions on simulator & $4(4,5)$ & $5(4,5)$ \\
\hline Simulated training sessions better than small group discussions & $5(4,5)$ & $5(4,5)$ \\
\hline HFS should be used more often in the teaching of clinical pharmacology & $4.5(4,5)$ & $5(4,5)$ \\
\hline $\begin{array}{l}\text { HFS is an effective tool to teach clinical drug therapy in: } \\
\text { Acute severe asthma } \\
\text { Status epilepticus }\end{array}$ & $5(4,5)$ & $5(4,5)$ \\
\hline $\begin{array}{l}\text { I am confident in managing a patient with: } \\
\text { Acute severe asthma in real life } \\
\text { Status epilepticus in real life }\end{array}$ & $4(4,4)$ & $4(4,4)$ \\
\hline
\end{tabular}

HFS: High fidelity simulations

1. Strongly disagree 2. Disagree, 3. Neither agree nor disagree, 4. Agree, 5. Strongly agree

Table 2: Responses to post simulation stress assessment

\begin{tabular}{|l|c|c|}
\hline \multirow{2}{*}{} & \multicolumn{2}{c|}{ Level of stress experienced in Likert scale } \\
\cline { 2 - 3 } & Status epilepticus session & Acute asthma session \\
\cline { 2 - 3 } & Median (Q1,Q3) & Median (Q1,Q3) \\
\hline Difficult in understanding the content & $3(2,3)$ & $2(2,3)$ \\
\hline Need to do well (self-expectation) & $3(2.75,4)$ & $2(2,4)$ \\
\hline Competition with team members & $2(1,3)$ & $2(1,3)$ \\
\hline Shortage of time during training session & $3(2,3.25)$ & $3(2,4)$ \\
\hline Feeling of incompetence in managing the patient & $3(2,4)$ & $2(1,2)$ \\
\hline Conflict with other students & $3(2,4)$ & $3(2,4)$ \\
\hline Need to participate in scenario & $3(2,4)$ & $2(1,3)$ \\
\hline Participation in debriefing & $2(1,3)$ & $2(1,3)$ \\
\hline Poor motivation to participate in session & $2(1,3)$ & $2(1,2)$ \\
\hline Lack of guidance from the teacher & $2(2,3)$ & $2(2,2)$ \\
\hline Not knowing my role in the team & $2(1,3)$ & $2(1,3)$ \\
\hline Lack of appreciation to my contribution in the team & $3(2,4)$ & $3(1,3)$ \\
\hline Instructor is observing & $3(2,4)$ & $2(1,3)$ \\
\hline My fellow batch mates are observing & $3(2,4)$ & $3(1,4.75)$ \\
\hline I am worried about patient outcome & $3(2,4)$ & $3(2,4)$ \\
\hline Because of my performance anxiety & $2(2,4)$ & \\
\hline
\end{tabular}

1. No stress 2. Low stress 3. Moderate stress 4. High stress 5.Maximum stress

\section{Discussion}

Students frequently fail and find it difficult to remember the drugs and doses used for the management of acute medical conditions. This knowledge is frequently and essentially tested in their medical training ${ }^{17}$. It is also vital to retain this knowledge in managing patients in real life. Status epilepticus and acute severe asthma are two important scenarios that students will encounter in their future profession. They should be armed with the knowledge and skills in order to provide patient care falling within accepted standards. It is shown that when knowledge is gained in the context where it would be practised (context based learning), it is best retained. Students have agreed that in our new teaching method using high fidelity patient simulation, the training session resembled a real life situation (median $4(4,5))$ and it encouraged their active participation $(4,(4,5))$. Study done by Pal B, et al on the use of HFS as a teaching method also shows that HFS could be used to make the scenarios resemble real life situations ${ }^{13}$. It is important that the scenario is run in the required direction for students to get the knowledge of managing the patients. This is not an easy task and the scenario may run in an awkward direction due to errors and faults. When it is allowed to happen like this, it is called the run though method and the risk is that students might not get the expected knowledge. There are two methods of correcting such deviations and 
making sure that the students are getting the expected knowledge. One method is to pause and redirect; yet, the problem is that the flow of the scenario is interrupted. The other method, which we employed, is to keep a knowledgeable actor within the scenario to correct the deviations without affecting the realism of it. This actor is called a 'confederate'. This way, we were able to run through the scenario uninterrupted as well as not allowing it to deviate in unintended directions.

HFS scenario should be commensurate with the existing knowledge of the students to get the maximum knowledge benefit. In our study, the participants were final year medical students who have gone through most part of their medical training. Students did agree that the session level was compatible with their knowledge and experience (median 4).

Consolidation of the knowledge gained during simulation happens in the post-event discussion (debriefing). It is important that correct debriefing techniques are utilised to achieve this. We use three techniques for this purpose, namely directive feedback, learner self-assessment and facilitated reflection. Out of these, facilitated reflection is the most advanced and it involves self-understanding of own deficiencies facilitated by the teacher ${ }^{18}$. This method is known to result in better retention of knowledge. However, successful debriefing needs advanced input from the teacher.

The students did score significantly higher for the posttest when compared to the pre-test $(p<0.001)$ for both simulation sessions. This shows that the students certainly gained the knowledge required to manage acute conditions in this scenario based learning. Since we have not assessed the knowledge, later on, we are unable to show the effect on retaining knowledge in the long term.

Regarding the teaching method, they felt that this was a valuable use of their time and that HFS is an effective tool to teach drug therapy. They also mentioned that HFS should be used more often in teaching clinical pharmacology. Further, they mentioned that the simulated sessions are better than small group discussions (Table 1) which indicates that this method of teaching is accepted well by the students. Regarding the learning outcomes, they mentioned that they feel confident in managing a patient with status epilepticus and acute severe asthma and that the simulated sessions contributed to their understanding of drug therapy in the above acute conditions (Table 1).

The HFS sessions were run in series. During the second session the overall moderate stress items were less, compared to the first session. This shows that by repeated exposure to simulations the students gain skills to face emergencies with less stress, which might improve their performance as well as knowledge gain.
However, the use of high fidelity simulation as a teaching method has its own limitations. Scenario preparation, faculty development, training and practicing scenarios with assistants is time consuming. This involves a lot of teacher time. On top of that, finding time allocations for the teaching sessions from the timetable is one of the most difficult tasks. However, students should not be deprived of the benefit of HFS as it is shown to be an effective method of teaching which is well received by the students.

There were some limitations of the study. The study involved a limited number of students. However, the results of the study are encouraging. The knowledge gain of the students was assessed only once after the simulation. Knowledge assessment with further sessions is suggested to assess the retaining of the knowledge. The study involved only the final year undergraduates. Since pharmacology teaching is mainly done during the third year, the value of HFS for third year students need to be assessed in future studies.

\section{Conclusions}

High fidelity simulation seems to be an effective way of teaching therapeutics in paediatrics and it is well received by the students.

\section{References}

1. Oshikoya KA, Senbanjo IO, Amole OO. Interns' knowledge of clinical pharmacology and therapeutics after undergraduate and ongoing internship training in Nigeria: a pilot study. BMC Medical Education 2009; 9(1): 50. https://doi.org/10.1186/1472-6920-9-50 PMid: 19638199 PMCid: PMC2724475

2. Walley T, Bligh J, Orme M, Breckenridge A. Clinical pharmacology and therapeutics in undergraduate medical education in the UK: current status. British Journal of Clinical Pharmacology 1994; 37(2): 129-35. https://doi.org/10.1111/j.13652125.1994.tb042 52.x

PMid: 8186059 PMCid: PMC1364589

3. Richir MC, Tichelaar J, Geijteman EC, de Vries TP. Teaching clinical pharmacology and therapeutics with an emphasis on the therapeutic reasoning of undergraduate medical students. European Journal of Clinical Pharmacology 2008; 64(2): 217-24. https://doi.org/10.1007/s00228-007-0432-z PMid: 18228012 PMCid: PMC2235908

4. Norman GT, Schmidt HG. The psychological basis of problem-based learning: A review of the evidence. Academic Medicine 1992; 67(9): 557-65.

https://doi.org/10.1097/00001888-19920900000002 
5. Coles C. How students learn: the process of learning. In: Jolly B, Rees L, editors. Medical Education in the Millennium. Oxford University Press; 1998: p.63-82.

6. Barsuk JH, McGaghie WC, Cohen ER, O’Leary KJ, Wayne DB. Simulation-based mastery learning reduces complications during central venous catheter insertion in a medical intensive care unit. Critical Care Medicine 2009; 37(10): 2697-701. https://doi.org/10.1097/00003246-20091000000003

PMid: 19885989

7. McGaghie WC, Issenberg SB, Petrusa ER, Scalese RJ. A critical review of simulationbased medical education research: 2003-2009. Medical Education 2010; 44(1): 50-63. https://doi.org/10.1097/00003246-20091000000003

PMid: 19885989

8. Wayne DB, Didwania A, Feinglass J, Fudala MJ, Barsuk JH, McGaghie WC. Simulationbased education improves quality of care during cardiac arrest team responses at an academic teaching hospital: a case-control study. Chest 2008; 133(1): 56-61.

https://doi.org/10.1378/chest.07-0131

PMid: 17573509

9. Regehr G, Norman GR. Issues in cognitive psychology: implications for professional education. Academic Medicine 1996; 71(9): 998-1001.

https://doi.org/10.1097/00001888-19960900000015

10. Gordon JA, Wilkerson WM, Shaffer DW, Armstrong EG. "Practicing" medicine without risk: students' and educators' responses to high-fidelity patient simulation. Academic Medicine 2001; 76(5): 469-72.

https://doi.org/10.1097/00001888-20010500000019

PMid: 11346525

11. McIvor WR. Experience with medical student simulation education. Critical Care Medicine 2004; 32(2): 66-9.

https://doi.org/10.1097/01.CCM.0000110737.8 3477.0F

PMid: 15043233

12. Malakooti MR, McBride ME, Mobley B, Goldstein JL, Adler MD, McGaghie WC. Mastery of status epilepticus management via simulation-based learning for paediatrics residents. Journal of Graduate Medical Education 2015; 7(2): 181-6.
https://doi.org/10.4300/JGME-D-14-00516.1

PMid: 26221431 PMCid: PMC4512786

13. Pal B, Kumar MV, Soe HH, Pal S. A study on the usefulness of high fidelity patient simulation in undergraduate medical education. The Asia Pacific Scholar 2018; 3(1): 42-49.

https://doi.org/10.29060/TAPS.2018-31/SC1059

14. Branch C. Pharmacy students' learning and satisfaction with high-fidelity simulation to teach drug-induced dyspepsia. American Journal of Pharmaceutical Education 2013; 77(2): 30 .

https://doi.org/10.5688/ajpe77230

PMid: 23519773 PMCid: PMC3602854

15. Topjian AA, Gutierrez-Colina AM, Sanchez SM, Berg RA, Friess SH, Dlugos DJ, et al. Electrographic status epilepticus is associated with mortality and worse short-term outcome in critically ill children. Critical Care Medicine 2013; 41(1): 210.

https://doi.org/10.1097/CCM.0b013e31826680 35

PMid: 23164815 PMCid: PMC3531581

16. Via DK, Kyle RR, Trask JD, Shields CH, Mongan PD. Using high-fidelity patient simulation and an advanced distance education network to teach pharmacology to second-year medical students. Journal of Clinical Anesthesia 2004; 16(2): 144-51.

https://doi.org/10.1016/j.jclinane.2003.09.001

PMid: 15110381

17. Larsen DP, Butler AC, Roediger III HL. Testenhanced learning in medical education. Medical Education 2008; 42(10): 959-66. https://doi.org/10.1111/j.13652923.2008.0312 4.X

PMid: 18823514

18. Eppich W, Cheng A. Promoting excellence and reflective learning in simulation (PEARLS): development and rationale for a blended approach to health care simulation debriefing.

Simulation in Healthcare 2015; 10(2):106-15. https://doi.org/10.1097/SIH.000000000000007 2

PMid: 25710312 